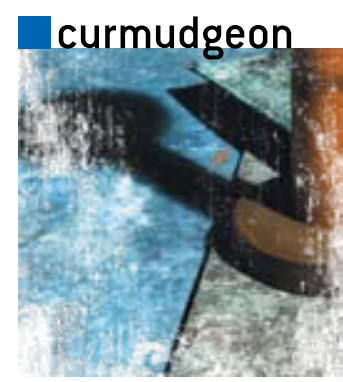

Is there an "out there" out there?

\title{
The Fabrication of Reality
}

Stan Kelly-Bootle, Author

T here are always anniversaries, real or concocted, to loosen the columnist's writer's block and/or justify the intake of alcohol. I'll drink to that-to the fact that we are blessed with a reasonably regular solar system providing a timeline of annual increments against which we can enumerate and toast past events. Hic semper hic. When the drinking occurs in sporadic and excessive bursts, it becomes known, disapprovingly, as "bingeing." I'm tempted to claim that this colorful Lincolnshire dialect word binge, meaning soak, was first used in the boozing-bout sense exactly 200 years ago. And that, shurely, calls for a schelebration. ${ }^{1}$ When I was lecturing (briefly) in Soviet Union ${ }^{2}$ pre-perestroika, the anniversary-induced tipple was as richly refined as the Stoli (Stolichnaya) vodka. You might call it the microbrewed anniversary: "Exactly 43 years 2 months 6 days ago, Vladimir Ilyitch took delivery of People's Blue Rolls-Royce!"

I can't be as precise, but I feel that a significant point in my own inscrutable timeline is struggling to assert itself. Therefore, let us celebrate my first encounter with David Deutsch's FOR (The Fabric of Reality), published almost exactly 10 years ago, give or take a few Min Planck units. ${ }^{3}$ At that first scan, I had formed distinctly mixed feelings about my dear old Deutsch. While agreeing with his pro-Karl Popperism and the central importance of the Turing principle and virtual reality computers, I was annoyed by his confused and confusing views on "The Nature of Mathematics" (chapter 10). An unexpected package in the mail from Bob Toxen last month, containing a slightly foxed copy of FOR, gave me the opportunity to reread and rejudge.

I'm now more sympathetic to his grand tour. His destination is: What's really going on "out there"? Of course, we need first to agree that there is an "out there" out there, to which we can apply the term reality. We may disagree in detail as to what is "knowable-for-certain" about this outside reality, and what is merely plausible conjecture. Some of our observations and perceptions are surely inconsistent and misleading, but unless you accept that something out there is "kicking back," you must kindly leave our stage and find another. "Solipsists of the world, unite" and leave us alone! And what on earth are you doing reading my column?

There are four FOR strands in Deutsch's attempt to grab the ultimate Holy Grail: Popperian epistemology; Darwinian/Dawkinsian evolution; QM (quantum mechanics); and CS (computing science) including, especially, the strong Turing principle and QC (quantum computing). Starting with what will probably shock you the most: Deutsch asserts the inescapable reality of parallel universes. Those weird multi-slit photon interferences that so bedeviled the early quantum pioneers imply an MV (multiverse). It's worth stressing that under Karl Popper's theory of scientific knowledge, some future "better" hypothesis could conceivably replace or modify FOR's MV hypothesis. But MV signals an end to the metaphysical speculation known as the Copenhagen Interpretation, which drags in weird interactions between human consciousness and atomic particles at the moment of observation. Some think that the enormous profligacy of all those parallel universes splitting off at the drop of a slit is too big a price to pay! Yet, is that just our finite minds seeking a parsimony that has no place in the fabric of reality?

We next consider Deutsch's views on the nature of scientific theory and its evolution, where, incidentally, he dismisses the relevance of Kuhnian paradigm shifts. He places priority on a theory's power of explaining reality, as opposed to the "instrumentalists" who place the emphasis on a theory's ability to make correct predictions. FOR makes the point that making false predictions rules out a theory. But of two theories that both make good predictions, you go for the one that offers the better explanations. Here, I detect a weakness, in that FOR does not deal with the intrinsic subjectivity of explanations. Of course, you must assume some kind of select "elite" capable of understanding and comparing the explanatory powers of, say, Deutsch's and Hawkings's cosmologies. Further, FOR skims over the semantic problems involved in NL (natural language), which, ultimately, is the only real 
vehicle available to explainers and explainees! The use of graphs and mathematical symbols can reduce NL's innate ambiguities, but (my heavy hobbyhorse) we need NL to ask, "What does your Sigma mean?"

Here's a brief example from the new Folio Society's divine two-volume edition of Newton's Principia. Undoubtedly the most influential scientific treatise in history, its original Latin is a huge challenge for translators who need to combine exceptional language and mathematical skills. Archaic mathematical terms such as subsesquiplicate ratio are easily modernized, but many of Newton's words are neologisms not found in classical Latin. The very notion of "rigorous proof" has changed since 1686 , of course, so modern translations often amplify the text or change geometrical proofs into modern algebraic proofs. In Newton's very first definition, though, we hit an intrinsic NL problem. The Latin says, "Quantitas materiae est mensura ejusdem..." For more than 300 years this was translated, "Quantity of matter is the measure of [matter that arises from its density and volume jointly]." The Folio translators (I. Bernard Cohen and Anne Whitman assisted by Julia Buzenz), however, have "Quantity of matter is a measure..." Did Sir Isaac mean "the measure" or "a measure"? Alas, Latin has that very quirk we noted in Russian: no definite or indefinite articles. $^{4}$

FOR is deliberately vague, but vaguely optimistic, on the practical future of QC (quantum computing). It seems part of the FOR package that our current intractability problems with classical Turing machines will be solved eventually with quantum computers or some as-yetunknown technology. Deutsch explains the challenge as engineering "sub-microscopic systems in which information-carrying variables interact among themselves but affect their environment as little as possible." My feeling is that FOR's prediction made in 1997 that "more complex special-purpose quantum computers will appear in a matter of years rather than decades" is already looking overly optimistic. Cynics, though, point to at least one parallel universe where Deutsch's prophecies have all been fulfilled. Needless to say, he has heard all such jokes before.

For a change of perspective, let's see what the philosophers make of this reality thingy. After all, it has been their midden for many a century, long before even Plato concluded that there were universal forms and mathematical objects lurking out there, somehow "kicking back" at those who thought about them. With the threatened emergence of TUI (tangible user interface), the more we know about sensory perception the better. I suggest Professor Paul Coates's The Metaphysics of Perception: Wilfrid Sellars, Perceptual Consciousness and Critical Realism (Routledge, 2007), mainly because I've dined with him, albeit under false pretenses. It took a while to realize that he was not the Professor Paul Coates I thought I was dining with. The latter teaches film at Aberdeen University, the former philosophy at Hertfordshire. Coates the philosopher looked blank when I told him how much I had enjoyed his books on Andrzej Wajda and Krzysztof Kieslowski. A more perceptive philosopher might have deduced the source of the error, but apparently he was unaware of his namesake and his namesake's favorite movie-makers. I hope I've cleared up any confusion in your minds.

Paul's book is a hefty $\$ 110$, but you have to pay for those essay-long philosophical titles. For $\$ 42.63$ via IngentaConnect, you can get the gist of his thesis from his paper "Perception and Metaphysical Scepticism" (Proceedings of the Aristotelian Society, 1998). These ideas are more relevant to ACM readers than you might imagine, given the new extended ACM Communications. They cover the rich domain often called "mind and machine," where rival theories of perception tussle for prominence. Are you a causalist or a disjunctivist? The causalist treats the sensory experience and the physical object perceived as distinct existences, whereas the disjunctivist claims that we "perceive physical objects directly, without being aware of any intervening states of mind, or entities such as sense data or the like" [op. cit.]. Paul Coates and I are both causalists, but it takes many pages (not to mention 45 footnotes) to clarify all the obvious objections, such as hallucinations and deviant causal chains, which occur in the disjunctivist literature. Both schools continue to look each way before crossing the road, recalling that the drivers in some countries (which shall be nameless) are daft enough to drive on the wrong side. The mantra in the UK, by the way, is "Look right, look left, then look right again." Your directions may vary. Else, the perception of a vehicle may break the perception of your skull.

\section{L'AFFAIRE LEDIN REDUX}

You may recall my report (ACM Queue, January 2008) that George Ledin, computer science professor at Sonoma State University, California, has attracted angry objections to his courses on malware. The antivirus industry, in particular, feels that Ledin's graduates have no business learning how viruses and other invasive nasties are constructed, nor being shown how easy it is to circumvent the defenses sold by the leading antiviral marketeers. Ledin tells me that John Aycock at Calgary University, 
Canada, has been engaged in similar battles for several years. Aycock's book, Computer Viruses and Malware (Advances in Information Security), was published by Springer-Verlag in 2006, so there's no hiding of the basic techniques unless certain Hitlerian incineration methodologies are invoked. A search of the ACM Digital Library for "John Aycock Malware" yields 13 matches, to which one can add Ledin's own paper, "Not teaching viruses and worms is harmful" (Communications of the ACM, January 2005). John Sullins, professor of philosophy at Sonoma State, has also been lending moral-ethical support to Ledin's malware courses. "We must teach it because it allows us to deal with the [dangerous] reality that our students are going to face." But Sullins also points out that malware might have some beneficial applications. It could be used to combat a tyrannical government. I see some NRA Second Amendment echoes here: the right to bear malware as self-defense. $\mathbf{0}$

\section{REFERENCES}

1. These deliberately slurred misspellings have been popularized by the British satirical magazine, Private Eye. Its editor is fond of asking, "Shurely shome mishtake?" Lexicographers are no doubt debating whether these forms deserve to be blessed with dictionary entries. There are precedents for mispronounced and misspelled words usurping the previous "standards" (e.g., according to some scholars, bird was originally brid.)

2. Another popular verbal tic is deliberately omitting
English definite and indefinite articles to mirror the famous quirk in Russian language!

3. Min (Minna; Wilhelmina) Planck belongs to that growing bunch of neglected sisters, such as Fanny Homer, Nannerl Mozart, Siobhan Shakespeare, and Doreen Kelly-Bootle, who quietly produced their brothers' works without fuss or fame. It's quite clear that Max had nothing to do with those tiny natural units of mass, length, and time. It was Min, Min all the way. 4. See reference 2 .

\section{LOVE IT, HATE IT? LET US KNOW}

feedback@acmqueue.com or www.acmqueue.com/forums

STAN KELLY-BOOTLE (http://www.feniks.com/skb/; http:// www.sarcheck.com), born in Liverpool, England, read pure mathematics at Cambridge in the 1950s before tackling the impurities of computer science on the pioneering EDSAC I. His many books include The Devil's DP Dictionary (McGrawHill, 1981), Understanding Unix (Sybex, 1994), and the recent e-book Computer Language-The Stan Kelly-Bootle Reader. Software Development Magazine has named him as the first recipient of the new annual Stan Kelly-Bootle Eclectech Award for his "lifetime achievements in technology and letters." Neither Nobel nor Turing achieved such prized eponymous recognition. Under his nom-de-folk, Stan Kelly, he has enjoyed a parallel career as a singer and songwriter. He can be reached at curmudgeon@acmqueue.com. (c) 2008 ACM $1542-7730 / 08 / 0700 \$ 5.00$

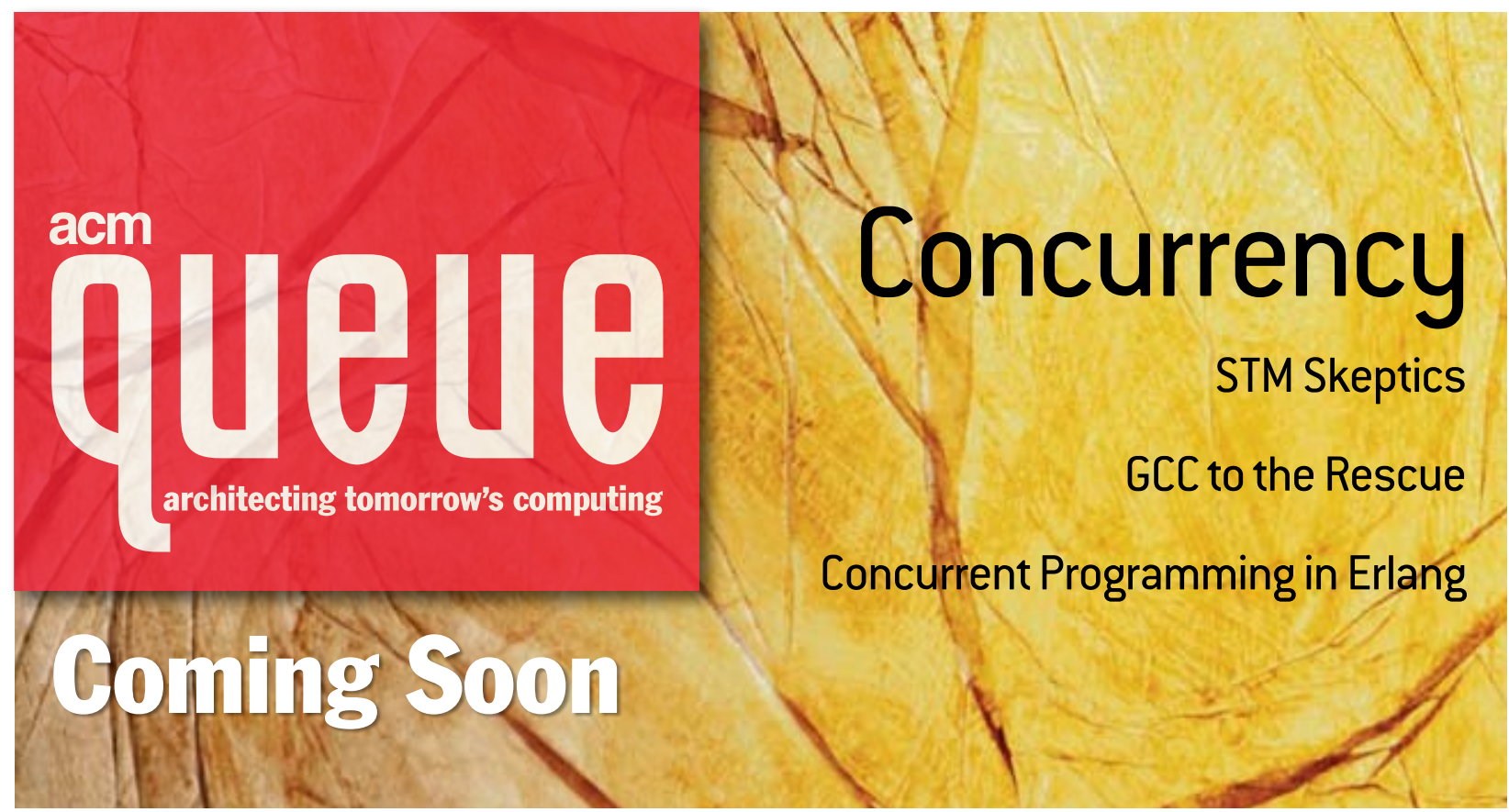

